\title{
Iatrogenic Aspiration of Custom-Made Keel: A Case Report
}

\author{
Hadi Sharouny ${ }^{1,3} ;$ Rahmat Bin Omar $^{2}$ \\ ${ }^{1}$ Department of Otorhinolaryngology Head and Neck Surgery, Shiraz University of Medical Sciences, Shiraz, IR Iran \\ ${ }^{2}$ Department of Otorhionlaryngology Head and Neck Surgery, University of Malaya, Kuala Lumpur, Malaysia \\ ${ }^{*}$ Corresponding Author: Hadi Sharouny, Department of Otorhinolaryngology Head and Neck Surgery, Shiraz University of Medical Sciences, Shiraz, IR Iran. Tel: +98-7116291478, Fax: \\ +98-7116291478, E-mail: hadi.sharouny@iran.ir.
}

Received: December 23, 2013; Revised: September 27, 2014; Accepted: October 6, 2014

\begin{abstract}
Introduction: Laryngeal stenosis has various causes and treatment options. Endoscopic resection of the stenotic part with $\mathrm{CO}_{2}$ laser is one of the treatment options of laryngotracheal stenosis. Keels are useful for preventing adhesion formation, restenosis and web formation, which may happen during the later stage. They can be put in place either via the endoscopic approach or through a micro thyroidotomy and are held in place with a heavy suture through cricothyroid and thyrohyoid membranes. They are left in place for two to four weeks, and then removed through the endoscopic approach under general anesthetics.

Case Presentation:We report on a case of anterior glottis stenosis with keel aspiration for two weeks, after endoscopic $\mathrm{CO}_{2}$ laser resection of the stenotic section and keel placement. The patient was admitted to our center, where bronchoscopy was performed and the keel was removed.A new custom-made silastic keel was properly placed in raw areas and fixed to the skin with suture through the cricothyroid and thyrohyoid membranes. The keel was removed three weeks later.

Conclusions: Endoscopic keel placement should be done with heavy suture through cricothyroid and thyrohyoid membranes. Surgeons should suture the keel to the anterior laryngeal wall with specially designed Lichtenberger's needle-carriers to prevent complications such as keel aspiration, adhesion formation and imposing a second trip under general anesthetics, which put the patient at increased risk. The false vocal cord microflaps, as biological keels and a relatively new method may replace silastic keel placement in the future.
\end{abstract}

Keywords:Laryngostenosis; Prosthesis Implantation; Laryngeal Diseases; Stents

\section{Introduction}

Laryngotracheal stenosis has a large number of etiologies (1). The leading causes of upper airway stenosis are prolonged endotracheal intubation and external trauma to the neck (1). Selection of appropriate surgical management of upper airway stenosis depends on location, severity, duration, etiology and extent of functional impairment (1). Stenotic sections can happen at different locations such as supraglottis, anterior glottis, etc. Surgical management of laryngotracheal stenosis ranges from tracheostomy to tracheal resection with postoperative stent placement (1). Keels are used to prevent adhesion formation in anterior glottic webs (1). We report on a patient with keel aspiration postoperatively. The aim of the present case report was to emphasize the importance of fixing keels properly on anterior commissure of the larynx.

\section{Case Presentation}

A 30-year-old man with a history of car accident and diagnosis of anterior glottic stenosis on tracheostomy tube was admitted to the University of Malaya Medical Centre, Kuala Lumpur, Malaysia in January 2012. Endoscopic carbon dioxide $\left(\mathrm{CO}_{2}\right)$ laser-assisted resection was done for this patient. A custom-made laryngeal keel, which was made from a silastic sheet, with $0.3 \mathrm{~mm}$ thickness, was placed endoscopically to cover the entire raw edge. Using a Lichtenberger endo-extralaryngeal needle carrier (Prolene 2.0), the silastic sheet was anchored to another silastic sheet on the skin. The patient was discharged with a prescription of oral omeprazole $20 \mathrm{mg}$, once a day, on the following day. He came back to the clinic two weeks after the operation with complaint of itchiness in his throat, abnormal sensation in his chest and blood stained phlegm. On cervical inspection, the area around the suture was inflamed. Flexible nasolaryngoscopy revealed that the silastic sheet was dislodged. Using flexible bronchoscopy through the fenestra of tracheostomy tube, the silastic sheet was seen in the right main bronchus (Figure 1). The patient was admitted and flexible bronchoscopy was performed through the fenestra of the tracheostomy tube and the keel was removed. Mitomycin- $C$ was applied over the raw edges. A new custom-made silastic keel was inserted using a Lichtenberger endo-extralaryngeal needle-carrier and passing a 2.0 Prolene suture through the cricothyroid membrane inferiorly, keel and thyrohyoid membrane superiorly, to allow anchor to the skin. The patient was seen a week later at the clinic and as indicated by flexible nasolaryngos-

Copyright ( ) 2014, Iranian Red Crescent Medical Journal. This is an open-access article distributed under the terms of the Creative Commons Attribution-NonCommercial 4.0 International License (http://creativecommons.org/licenses/by-nc/4.0/) which permits copy and redistribute the material just in noncommercial usages, provided the original work is properly cited. 
copy, the keel was in situ. The subject was re-examined under general anesthetics three weeks post-operation and the silastic sheet was removed.

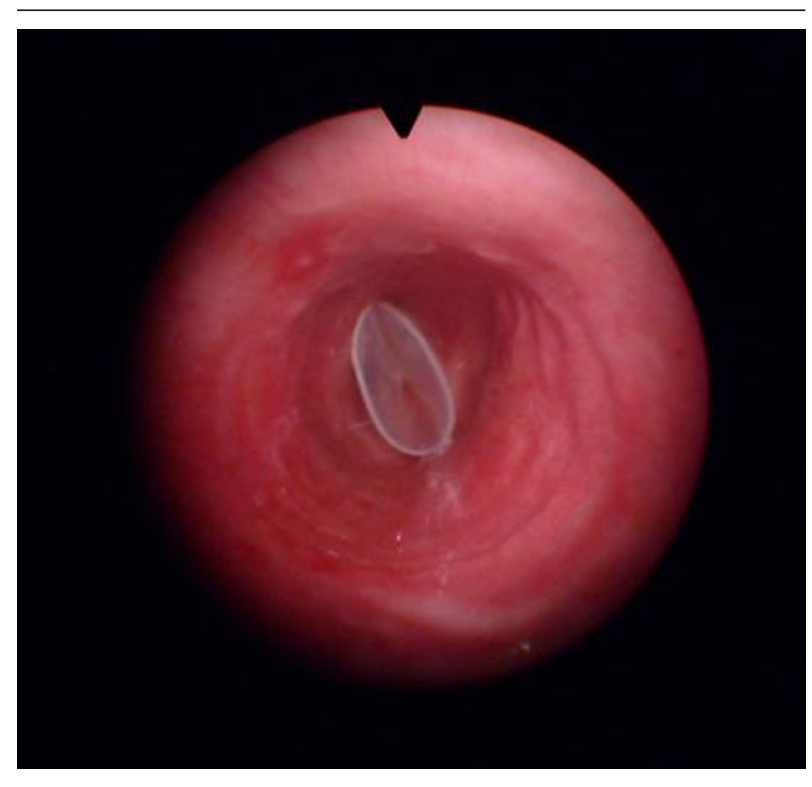

Figure 1. Bronchoscopic View of the Custom-Made Silastic Keel in the Right Main Bronchus

\section{Discussion}

The most prevalent etiology of adult laryngotracheal stenosis is internal laryngotracheal trauma including endotracheal intubation and tracheostomy (2). The other causes include radiotherapy, endotracheal burn, penetrating tissue injury, blunt neck trauma, bacterial infections, fungal infections, chronic inflammatory disease, collagen vascular disease, benign neoplastic diseases, extrinsic compression and malignancies $(1,2)$. Anterior glottic stenosis may be caused by thyroid cartilage fractures and internal laryngeal trauma, e.g. endotracheal tube or excessive resection of the anterior edges of both vocal cords at the same time $(1,2)$. A thin web that extends more than three to four millimeters posteriorly along the vocal fold can cause hoarseness, while a web that extends farther posteriorly or a thicker web can produce airway compromise (3). Management of laryngotracheal stenosis relies on the site which it occurs, namely, supraglottic, anterior glottic, posterior glottic, complete glottic, subglottic and tracheal stenosis $(1,2)$.

Endoscopic management of anterior glottic stenosis can be performed using either cold instruments or the $\mathrm{CO}_{2}$ laser, provided that the inferior edge of the true vocal cord is not involved and the posterior commissure is completely normal. If the anterior glottic stenosis is more extensive than described in the earlier paragraph or when endoscopic management is unsuccessful, the scar tissue should be excised through an open laryngofissure approach and any defect should be grafted (4).
Anterior glottic restenosis may occur during the healing process postoperatively. This complication rate has been reported to range from $7 \%$ to $47 \%$ in previous studies (5).

Mitomycin C is an antimetabolite agent which inhibits fibroblast proliferation (2). Topical mitomycin C can be helpful in treating and preventing consequent stenosis in the laryngotracheal area $(1,6,7)$. The use of mitomycin $C$ is still controversial $(6,7)$. Historically speaking, the first description of glottic web repair was provided in the late 19th century, in which a bougienage was employed many times (8). This technique had limited success due to the high level of scar formation and re-stenosis. By the mid-20th century, a number of procedures were defined yet each had its own challenges. These approaches had two steps in which the exposed mucosal surfaces reepithelialized with time. These methods were devised to keep apart the exposed mucosal surfaces, prevent scar formation and eventual recurrent webbing.

In 1950, McNaught described a method with tantalum keel placement via the laryngofissure approach as the first step of the process. The next step in the process was then done to remove the keel via the open approach (9). The main disadvantages of McNaught's technique were that it required a tracheostomy and repeated open laryngofissure procedure for keel insertion and removal (5). The endoscopic approach described by Haslinger in 1922 revolutionized the problems encountered by McNaught's technique (10). Haslinger placed a sliver plate, which was bent half-way to fit anteriorly at the site of exposure by an endoscopic approach. The plate was secured by wires through the thyrohyoid and cricothyroid membranes (10). However, due to the low success rate surgeons abandoned this method.

Metal, Teflon, silicone, and silastic keels were used over time. To overcome the difficulty in passing sutures from the airway outward through the thyrohyoid and cricothyroid membranes an endo-extralaryngeal needle carrier was used (11). A silastic keel was utilized by Liyanage et al. (12). The keel was fixed by inserting a prolene suture through the cricothyroid membrane on the right into the air passage, through the keel, and out through the cricothyroid membrane on the left. The keel was kept in place for two weeks, and during the follow-up visit, after cutting the suture externally the keel was removed with laryngeal forceps. A similar silicone keel placement method was described by Edwards et al. in 2006. A 16-gauge angiocatheter was inserted through the inferior part of the cricothyroid membrane and then through the thyrohyoid membrane to fix sutures over a silicone button on the anterior cervical skin (5). The disadvantages of the techniques mentioned above include long-term intubation and prolonged glottic stenting e.g. keels, mechanical ventilation and tracheostomy. Furthermore, the keel is a foreign body in the airway, which may dislodge and lead to airway compromise or act as a focus of inflammatory reaction or infection.

McGuirt et al. in 1984, described the use of mucosal 
flaps in the management of anterior glottic webs (13). This technique is comprised of raising a mucosal flap which constitutes the actual lysed web to cover one vocal cord. Another technique was described by Schweinfurth in which the web is separated in two parts from the midplane, and flaps are placed bilaterally on each vocal cord and sutured together (14). The advantages of Schweinfurth's procedure are that it prevents prolonged glottic stenting with keels, endotracheal intubation, mechanical ventilation, and tracheostomy. The disadvantages of the current method are its major technical difficulties and the potential risk of exposed lamina propria, which can lead to the local spread of respiratory papillomas and fibrosis (14). Tissue fibrosis may cause loss of vibratory motion after some time. Schweinfurth also describes that this specific procedure may be less useful in cases with absence of the vocalis muscle or complete fibrosis of both vocal folds. Ghadiali et al. in 2009, described the use of a false vocal cord microflap as a biological keel in the management of anterior glottis webs (15). The use of false vocal fold microflaps will eliminate the risk of keel displacement in the airway (15).

Keels are helpful in preventing adhesion formation, consequent stenosis and web formation. Keels can be put in place either through the endoscopic approach or mini thyroidotomy. They are held in place with a heavy suture through the thyrohyoid and cricothyroid membranes. Keels should be left in place for two to four weeks and then removed endoscopically under general anesthetics so that any undesirable granulation tissue can also be removed at the same time $(1,3,16)$. To the best of our knowledge, this is the first case report of laryngeal stent aspiration as evidenced by extensive PubMed and English-literature search. Care should be taken to fix keels with suture to prevent complications such as silastic sheet aspiration that occurred in the current case and imposing a second trip under general anesthetics, which causes more risks for the patient. Negligence in diagnosing a dislodged keel may lead to adhesion formation. The mucosal microflaps from false cords are also a viable option for treating an anterior glottic web, which eliminates the risk of keel displacement and complications such as foreign body aspiration.

In conclusion, keels are used to prevent adhesion formation and are held in place with a heavy suture through cricothyroid and thyrohyoid membranes using the Lichtenberger endo-extralaryngeal needle-carrier $(1,11,17)$. Care should be taken to fix the keel in place to prevent complications such as aspiration and placing patients at greater risks. The mucosal microflaps as a relatively new method may replace keel placement in the future.

\section{Authors' Contributions}

Drafting of the manuscript and critical revision of the manuscript for important intellectual content: Hadi Sharouny. Study supervision: Rahmat Bin Omar.

\section{References}

1. Khalid AN, Goldenberg D. Surgical Management of Upper Airway Stenosis. In: Flint PW, Haughey BH, Lund VJ, Niparko JK, Richardson MA, Robbins KT editors. Cummings Otolaryngology Head \& Neck Surgery.; 2010. pp. 943-52.

2. Pitkin L. Laryngeal trauma and stenosis. In: Gleeson M, Browning GG, Burton MJ, Clarke R, Hibbert J, Jones NS editors. Scott-Brown's Otorhinolaryngology, Head and Neck Surgery.. London: HodderArnold; 2008. pp. 2271-85.

3. Dedo HH. Endoscopic Teflon keel for anterior glottic web. Ann Otol Rhinol Laryngol.1979;88(4 Pt 1):467-73.

4. Parker DA, Das Gupta AR. An endoscopic silastic keel for anterior glottic webs. J Laryngol Otol.1987;101(10):1055-61.

5. Edwards J, Tanna N, Bielamowicz SA. Endoscopic lysis of anterior glottic webs and silicone keel placement. Ann Otol Rhinol Laryngol. 2007;116(3):211-6.

6. Rahbar R, Valdez TA, Shapshay SM. Preliminary results of intraoperative mitomycin-C in the treatment and prevention of glottic and subglottic stenosis. J Voice. 2000;14(2):282-6.

7. Hartnick CJ, Hartley BE, Lacy PD, Liu J, Bean JA, Willging JP, et al. Topical mitomycin application after laryngotracheal reconstruction: a randomized, double-blind, placebo-controlled trial. Arch Otolaryngol Head Neck Surg. 2001;127(10):1260-4.

8. Von Schroetter L. [Lectures Regarding Diseases of the Larynx].Leipzig: Braumuller \& Wein; 1892.

9. McNaught RC. Surgical Correction of Anterior Web of the Larynx. Laryngoscope.1950;60(3):264-72.

10. Haslinger F. [A case of membrane formation in larynx, a new method of safer recovery]. Monatsschr Ohrenheilkd Laryngorhinol. 1924;22:174-6.

11. Lichtenberger G, Toohill RJ. New keel fixing technique for endoscopic repair of anterior commissure webs. Laryngoscope. 1994;104(6 Pt1):771-4.

12. Liyanage SH, Khemani S, Lloyd S, Farrell R. Simple keel fixation technique for endoscopic repair of anterior glottic stenosis. J Laryngol Otol. 2006;120(4):322-4.

13. McGuirt WF, Salmon J, Blalock D. Normal speech for patients with laryngeal webs: an achievable goal. Laryngoscope. 1984;94(9):1176-9.

14. Schweinfurth J. Single-stage, stentless endoscopic repair of anterior glottic webs. Laryngoscope. 2002;112(5):933-5.

15. Ghadiali MT, Nazarian R, Chhetri DK, Berke GS. Endoscopic Repair of Anterior Glottic Web Using a False Vocal Fold Microflap as a Biological Keel. Laryngoscope. 2009;119(S3):S266.

16. Gluecker T, Lang F, Bessler S, Monnier P, Meuli R, Schnyder P, et al. 2D and 3D CT imaging correlated to rigid endoscopy in complex laryngo-tracheal stenoses. Eur Radiol. 2001;11(1):50-4.

17. Lichtenberger G. Endo-extralaryngeal needle carrier instrument. Laryngoscope. 1983;93(10):1348-50. 